\title{
Analisis Penerapan Konsep Lean Manufacturing pada Penurunan Defect Knuckle Arm Steering dengan Metode PDCA di PT.PQR
}

\author{
Andira $^{1}$, Dwi Haryanto ${ }^{2}$ \\ Program Studi Teknik Industri, Fakultas Teknik, Universitas Presiden, \\ Jababeka Education Park, Jl. Ki Hajar Dewantara Kota Jababeka, Bekasi 17550, Indonesia \\ 1andira@president.ac.id, 2dwhryi@gmail.com
}

\begin{abstract}
Abstrak
PT.PQR merupakan perusahan yang memproduksi casting untuk produk otomotif. Berdasarkan data dari departemen Quality Control, terdapat beberapa produk dengan tingkat defect yang tinggi dan produk tersebut berstatus scrap sehingga efisiensi perusahaan menurun. Kondisi ini sangat merugikan bagi perusahaan karena akan menambah biaya yang seharusnya tidak perlu dikeluarkan. Oleh karena itu dilakukan penelitian penyebab terjadinya cacat dan solusi perbaikan. Hasil pengamatan didapatkan bahwa data selama Januari - Maret 2017 produk knuckle arm steering memiliki tingkat defect sebesar $20.04 \%$ dengan macro shrinkage sebagai penyumbang terbesar. Pada bulan Maret-Juli 2017 dilakukan upaya perbaikan dengan konsep lean manufacturing dengan metode PDCA. Hasil dari perbaikan ini memberikan perbaikan kualitas produk knuckle arm steering sehingga defect berkurang $15.01 \%$ menjadi $5.03 \%$. Kemudian biaya yang dikeluarkan sebelum perbaikan adalah Rp 2.626.160,- dan sesudah perbaikan menjadi Rp 2.224.890,- .
\end{abstract}

Kata kunci: knuckle arm steering, defect, biaya, lean manufacturing, macro shrinkage

\begin{abstract}
PT. PQR produces casting for automotive products. Based on data from the Quality Control department, there are several products with high defect levels and most of defect products are categorized as scrap that make the company's efficiency decrease. This condition is very detrimental to the company because it will add costs that should not be spent. Therefore, this research is conducted on the causes of defects for finding the solutions. The results of the observation showed that the data during January - March 2017 knuckle arm steering products had a defect rate of 20.04\% with macro shrinkage as the biggest contributor. In March-July 2017 improvements were made with the concept of lean manufacturing with the PDCA method. The results of these improvements provide improved quality of knuckle arm steering products so that defects are reduced by $15.01 \%$ to $5.03 \%$. Then the cost incurred before improvement is Rp. 2,626,160 and after improvement is Rp 2,224,890
\end{abstract}

Keywords: knuckle arm steering, defect, cost, lean manufacturing, macro shrinkage

\section{Pendahuluan}

PT.PQR merupakan manufaktur automotive component yang bergerak di bidang sand casting iron. Adapun produksi perusahaan ini antara lain flywheel, exhaust manifold, disc rotor, brake drum, body caliper, knuckle arm steering, dll. Berdasarkan data produksi PT.PQR, terdapat produk knuckle arm steering dalam pengawasan karena proses pembuatannya yang memiliki beberapa masalah dengan hasil akhir yang belum stabil sehingga berpotensi terjadi defect tinggi dan dapat menimbulkan dampak buruk bagi perusahaan.Adapun data dari departemen Quality Assurance pada bulan JanuariMaret 2017 persentase defect produk yang bermasalah di PT.PQR cukup tinggi yakni 20\% dan nilai ini telah melebihi standar defect $5 \%$. Tingginya persentase defect ini, diperlukan perbaikan untuk mencari solusi penanggulangan terjadinya defect dalam proses produksi dengan target menurunkan persentase menjadi 5\% agar dampak buruk bagi perusahaan tidak berkelanjutan serta dapat dikurangi sehingga dapat meningkatkan produktifitas dari perusahaan. Dengan demikian penurunan defect yang 
akan terjadi kualitas dan kapasitas produksi akan meningkat sehingga profit perusahaan akan bertambah.

Lean manufacturing adalah manajemen proses yang berasal dari Toyota Production System (TPS) dimana peniadaan pemborosan (waste) dititikberatkan dengan tujuan peningkatan kepuasan konsumen secara keseluruhan. Proses lean manufacturing adalah suatu upaya terus-menerus untuk menghilangkan pemborosan (waste), dan untuk meningkatkan nilai tambah (value added) produk (barang dan atau jasa), agar memberikan hasil kepada pelanggan (customer value). Lean manufacturing harus diimplementasikan secara berkelanjutan agar dapat menghasilkan peningkatan yang diharapkan perusahaan (Fontana dan Gasperz, 2011). Toyota mengidentifikasi berbagai jenis waste dalam lean manufacturing yaitu sebagai berikut (Liker, 2003): Over production, Waiting, Transportation, Over processing, Inventory, Motion, Defect, Unused employee's creativity. Jenis waste diuraikan menjadi tiga kategori yaitu muda, mura, dan muri Chaudhari, dan Raut, 2017). Pengertian istilah-istilah ini adalah sebagai berikut: (1) Muda, yaitu aktivitas yang tidak bermanfaat atau tidak memberi nilai tambah. (2) Mura, yaitu ketidakmerataan atau fluktuasi kerja. (3) Muri, yaitu sulit untuk dilakukan, tidak beralasan, atau irasional. Lean manufacturing diterapkan dengan beberapa tools yang memiliki metode berbeda-beda dan pada setiap metode memiliki karakteristik pemecahan masalah (Asefeso, 2012). Lean manufacturing tools yang dapat digunakan yaitu 5S, TPM, JIT, Kanban, dan TQM. Metode TQM yang dikenal luas adalah Metode W.E Deming yaitu siklus PlanDo-Check-Action (PDCA). PDCA adalah suatu metodologi pemecahan masalah iteratif yang banyak diaplikasikan untuk pengendalian mutu secara statitistik dan berkelanjutan. Metode ini digunakan untuk kegiatan perbaikan yang berkelanjutan. Tujuan dari penelitian ini adalah: (1) Untuk mengetahui penyebab terjadinya defect yang mempengaruhi produktivitas dari perusahaan. (2) Untuk mendapatkan solusi penanggulangan defect agar produktivitas perusahaan meningkat.

\section{Metode Penelitian}

Penelitian ini menggunakan pendekatan TQM dengan siklus metode PDCA agar proses perbaikan yang dilakukan secara sistematis dan terencana dengan baik. Metodologi penelitian dapat diperlihatkan pada Gambar 1 :

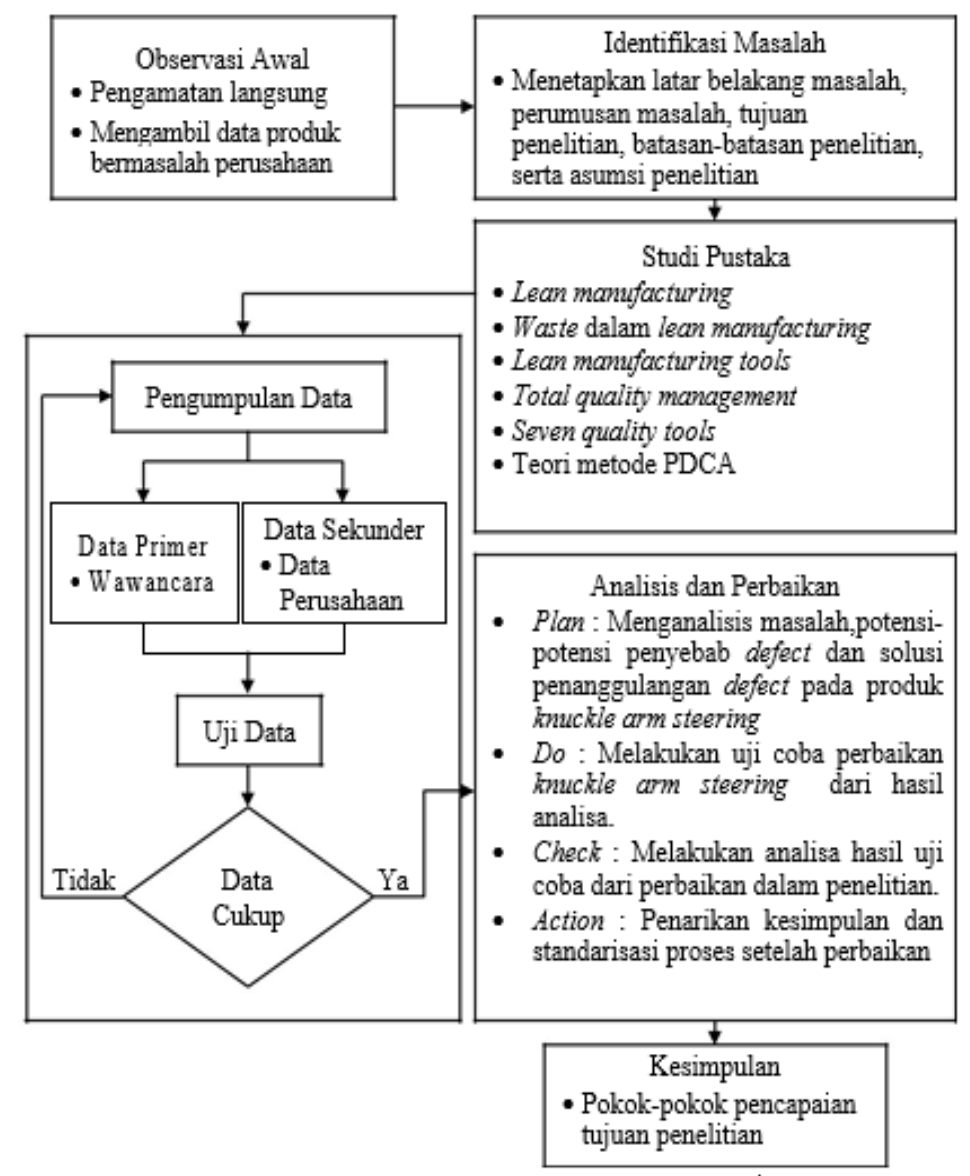

Gambar 1.Kerangka Metodologi Penelitian 


\section{Hasil dan Pembahasan}

\subsection{Tahap Plan}

Pada tahap perencanan (plan) dijabarkan kondisi permasalahan dan proses perencanaan terhadap sebuah penelitian untuk mendukung proses perbaikan. Proses Plan terdiri dari tahapan pengumpulan data dan selanjutnya dilakukan analisis dari data tersebut.

Tabel 1. Produk Dalam Pengawasan

\begin{tabular}{|c|c|c|c|c|c|}
\hline NO & PART NAME & PART NUMBER & CUSTOMER & ILUSTRASI PRODUK & PROBLEM \\
\hline 1 & Knuckle Arm S & 43211-0D290 & ADMTMMIN & & Macro Shrinkage \\
\hline 2 & Presure Plate 70510 & $321121-60221$ & ADNTMMIN & & Slag Inclusion \\
\hline 3 & Presure Plate 70200 & 321121-40250-A & ADMTMMIN & & Sand Inclusion \\
\hline 4 & Presure Plate 70560 & $321121-70510$ & ADNTMMIN & & Sand Inclusion \\
\hline 5 & Retainer $614 \mathrm{~K}$ & 333131-55100 AAT & DSPC & & Sand Inclusion \\
\hline 6 & Presure Plate D38A & $321121-02006$ & ADMTMMIN & & Slag Inclusion \\
\hline 7 & Presure Plate 40250 EFC & 13405-BZ110 & ADMTMMIN & & Sand Inclusion \\
\hline 8 & Carrier Differential & MB393294 & MKM & & Cold Lap \\
\hline 9 & Presure Plate 60690 & 33119-0К030 & ADNTMMIN & & Sand Inclusion \\
\hline 10 & Presure Plate 60221 & $321121-70190$ & ADMTMMIN & & Sand Inclusion \\
\hline 11 & FW - D40D & 13451-BZ060 & ADMTMMIN & & Sand Inclusion \\
\hline
\end{tabular}




\subsubsection{Pengumpulan Data}

Masalah yang menjadi perhatian pada penelitian ini yaitu produk bermasalah dengan defect tinggi. Tabel 1 memperlihatkan 11 tipe produk yang berada pada pengawasan karena total rejection tinggi dengan produk knuckle arm steering. Tabel 2 menjelaskan jumlah produksi dari data produk bermasalah, jumlah rejection serta ratio rejection dari produk yang bermasalah tersebut Dari produk tersebut terlihat bahwa defect yang ada mepengaruhi total rejection dari knuckle arm steering dan berimbas kepada keseluruhan total proses.

Tabel 2. Data Proses Produk Bermasalah

\begin{tabular}{|c|l|l|c|c|c|c|}
\hline \multirow{2}{*}{ No } & \multicolumn{2}{|c|}{ PART NAME } & \multirow{2}{*}{ PART NUMBER } & \multirow{2}{*}{ CUSTOMER } & \multicolumn{2}{c|}{ PROSES JANUARI-MARET 2017 } \\
\cline { 5 - 7 } & & & & QTY PROCESS (Pcs) & QTY REJECTION (Pcs) & Pcs (\%) \\
\hline \hline 1 & Knuckle Arm S & $43211-0 \mathrm{D} 290$ & ADMTMMIN & 62139 & 12450 & 20,04 \\
\hline 2 & Presure Plate 70510 & $321121-60221$ & ADMTMMIN & 39744 & 7692 & 19,35 \\
\hline 3 & Presure Plate 70200 & $321121-40250-A$ & ADMTMMIN & 61653 & 9366 & 15,19 \\
\hline 4 & Presure Plate 70560 & $321121-70510$ & ADMTMMIN & 23133 & 1275 & 5,51 \\
\hline 5 & Retainer 614K & $333131-55100$ AAT & DSPC & 34311 & 1695 & 4,94 \\
\hline 6 & Presure Plate D38A & $321121-02006$ & ADMTMMIN & 40998 & 2025 & 4,94 \\
\hline 7 & Presure Plate 40250 EFC & $13405-$ BZ110 & ADMTMMIN & 44256 & 2175 & 4,91 \\
\hline 8 & Carrier Differential & MB393294 & MKM & 22020 & 1065 & 4,84 \\
\hline 9 & Presure Plate 60690 & $33119-0 K 030$ & ADMTMMIN & 21924 & 966 & 4,41 \\
\hline 10 & Presure Plate 60221 & $321121-70190$ & ADMTMMIN & 76803 & 3345 & 4,36 \\
\hline 11 & FW - D40D & $13451-B Z 660$ & ADMTMMIN & 114999 & 4953 & 4,31 \\
\hline
\end{tabular}

\subsubsection{Analisis Proses Saat Ini}

\section{a. Pareto}

Dari beberapa produk yang mempunyai ratio rejection tertinggi knuckle arm steering dipilih dengan analisis pareto karena memberikan kontribusi proses yang signifikan terhadap seluruh proses produksi.

Tabel 3. Presentase Reject Produk Knuckle Arm Steering

\begin{tabular}{|c|c|c|c|c|}
\hline No & Part Name & $\begin{array}{c}\text { Jum lah Proses (pcs) } \\
\text { (Jan-Mar'17) }\end{array}$ & QTY REJECT (Pcs) & Presentase Reject (\%) \\
\hline \hline 1 & Knuckle Arm S & 62139 & 12450 & $20.04 \%$ \\
\hline
\end{tabular}

Gambar 2 menampilkan bentuk fisik dari produk knuckle arm steering. Gambar 3 ada desain pattern dari pencetakan casting knuckle arm steering. Gambar 4 menampilkan ilustrasi asembling knuckle arm steering pada kendaraan roda empat.

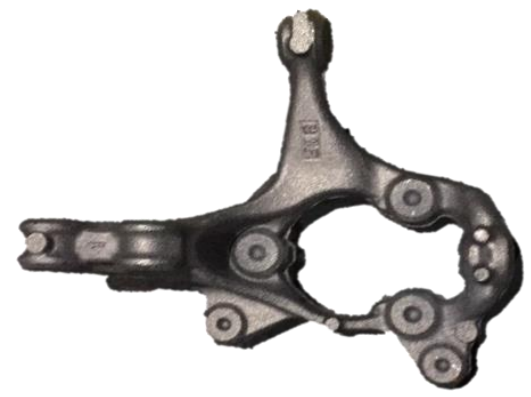

Gambar 2. Ilustrasi Produk Knuckle Arm Steering 




Gambar 3. Pattern Desain Gatting System Knukcle Arm Steering

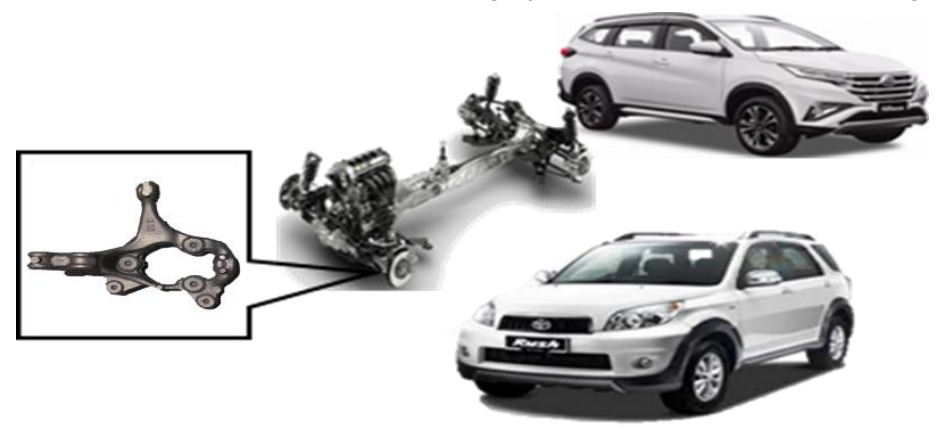

Gambar 4. Ilustrasi Pemasangan Knuckle Arm Steering Pada Kendaraan Roda Empat

Tabel 3 menjelaskan presentase total reject pada 3 bulan pertama yaitu sebesar 20.04\%. Jumlah tersebut sangat tinggi jika dibandingkan dengan target dari maksimal reject sebesar $5 \%$. Karena tingginya rejection inilah yang membuat perusahaan merugi dan merupakan pemborosan. Untuk menginginkan hasil akhir yang diinginkan perlu ditetapkan target. Target yang ditentukan bersifat SMART yang merupakan kepanjangan Spesific (jelas), Measurable (terukur), Achievable (tercapai), Reasonable (realistis/masuk akal), dan Time bound (jangka waktu). Penjabaran dari SMART yang ditentukan adalah sebagai berikut:

- Spesific: Proses produksi knuckle arm steering tidak efektif karena mempunyai rejection yang tinggi.

- Measurable: Menurunkan rejection dari $20.04 \%$ ke $5 \%$ sesuai kebijakan dari perusahaan.

- Achievable: Dengan melakukan analisis dari masalah yang ada

- Reasonable: Menurunkan defect akan meningkatkan efektivitas dan efisiensi dari perusahaan.

- $\quad$ Time Base : Dari April - Juni 2017

Dari penjelasan SMART diatas target penelitian adalah menurunkan rejection knuckle arm steering dari 20.04\% ke 5\% pada periode April-Juni 2017 dengan melakukan analisis masalah terhadap kondisi waktu sebelum periode penelitian.

b. Aliran Proses Produksi Knuckle Arm Steering 


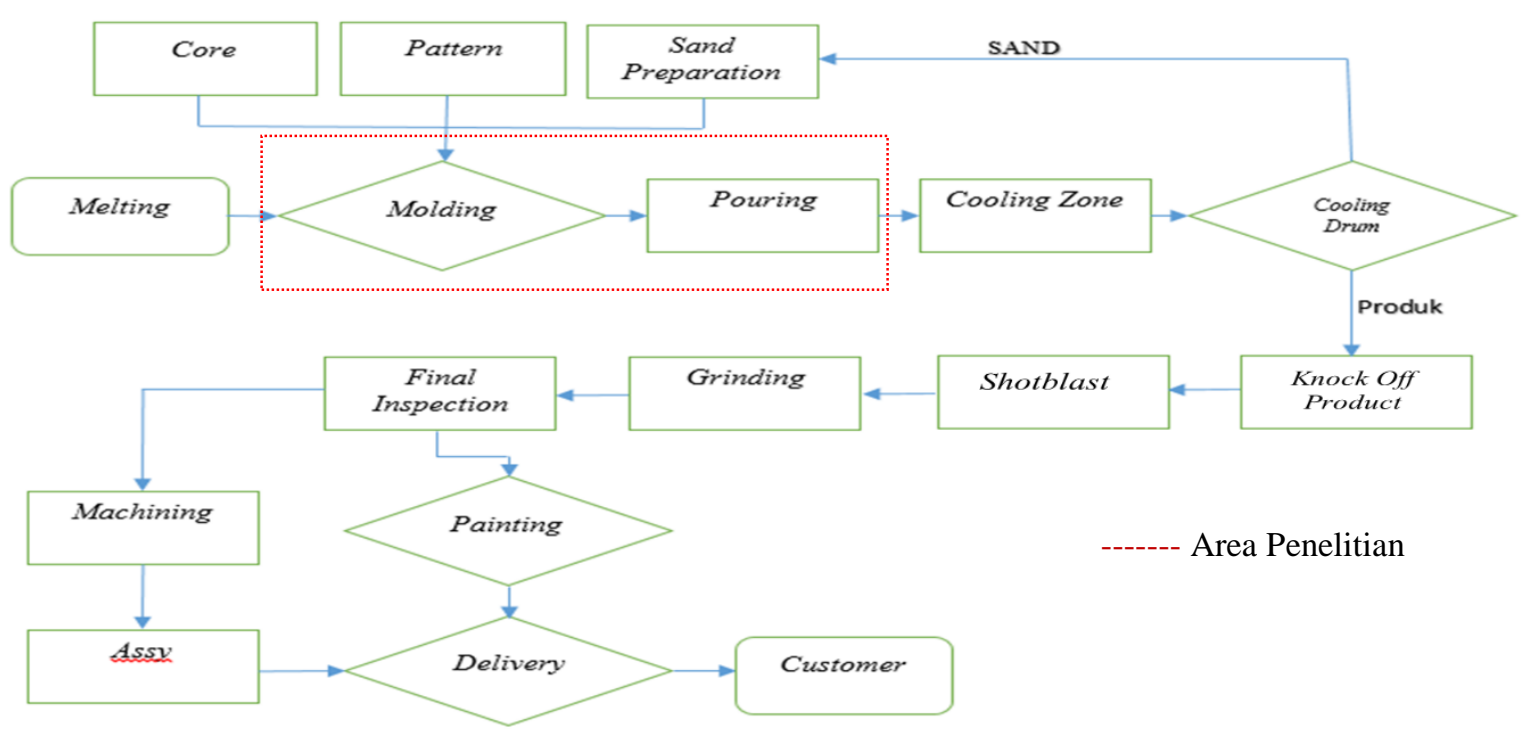

Gambar 5. Aliran proses produksi PT.PQR

Gambar 5 adalah aliran proses produksi,permasalahan yang sedang terjadi dari awal proses sampai menjadi barang jadi dianalisa untuk mencari tempat dimana terjadi permasalahan. Dalam pembuatan knuckle arm steering melewati beberapa mesin pada proses manufaktur, inti dari proses ini adalah proses pembuatan pasir cetak molding yaitu proses pembuatan produk sesuai alur pattern. Jika dilihat dari aliran proses, pembuatan produk berawal dari raw material metal chips dan alloy material yang di lebur pada bagian melting. Pada saat yang bersamaan mesin molding melakukan proses pembuatan media cetakan pasir sesuai kontur alur pattern. Pada proses penuangan, temperatur dari pasir cetak dan pattern dijaga pada suhu $40-60^{\circ} \mathrm{C}$ sedangkan molten iron pada dikisaran suhu $1400-1430{ }^{\circ} \mathrm{C}$, tujuannya adalah agar defect yang berhubungan dengan temperatur seperti macro shrinkage dapat di minimalisir.

Macro Shrinkage merupakan jenis defect dimana terdapat rongga di dalam coran akibat penyusutan saat pembekuan, defect ini timbul pada bagian coran yang mengalami pembekuaan paling lambat. Secara visual rongga ini hanya dapat dilihat pada daerah riser (setelah pemisahan riser) seperti yang terlihat pada Gambar 6 .

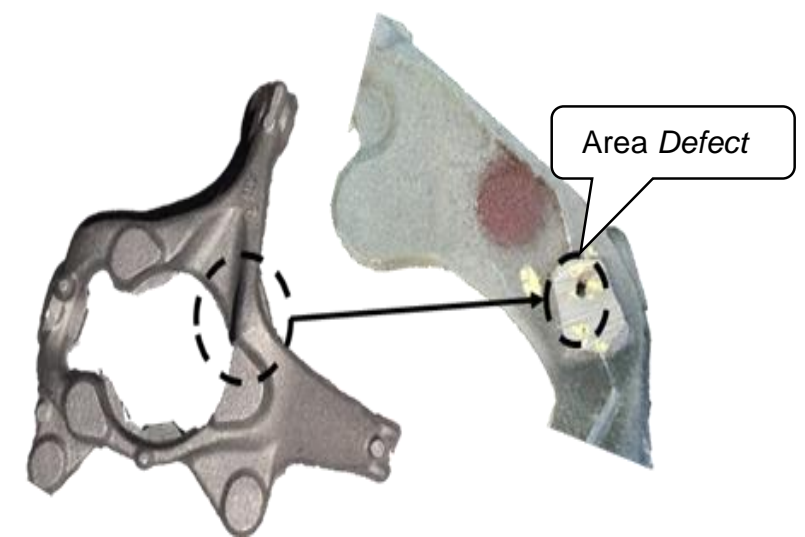

Gambar 6. Area Defect Macro Shrinkage Pada Knuckle Arm Steering

Dalam pembuatan produk knuckle arm steering sebelum adanya perbaikan berkemungkinan desain yang dipakai terjadi perubahan ukuran yang tidak tetap dan terjadi defect karena bahan yang dipakai sudah aus. Selain itu jika pattern dari produk knuckle arm steering belum masuk pada proses coating chrome sehingga desain pada profil dapat berubah-ubah. Sehingga diperlukan perbaikan untuk efektivitas proses pembuatan produk knuckle arm steering yang akan diproses produksi masal dan menghilangkan potensi terjadinya defect-defect yang lain. 


\section{c. Waktu dan Biaya Perbaikan Knuckle Arm Steering}

Setiap perbaikan memiliki perhitungan biaya sehingga akan berpengaruh pada total biaya produksi. Analisa perencanaan perbaikan harus benar-benar detail dikarenakan setiap perbaikan tidak langsung menyelesaikan masalah yang ada pada suatu produk sehingga perlu dilakukan uji coba lebih dari satu kali untuk mendapatkan hasil yang sesuai dan data yang akurat.Penentuan perencanaan perbaikan yang sesuai juga dapat mengefisiensikan total biaya yang keluar.

Tabel 4. Biaya Perbulan Perbaikan Pattern Proses Knuckle Arm Steering

\begin{tabular}{|c|c|c|c|c|c|}
\hline \multirow{2}{*}{$\begin{array}{c}\text { Process } \\
\text { Roughing Gatting System }\end{array}$} & \multicolumn{2}{|c|}{ Cost/Hour } & \multirow{2}{*}{$\frac{\text { Time (Hour) }}{1}$} & \multicolumn{2}{|c|}{ Cost (Rp) } \\
\hline & $\mathrm{Rp}$ & $550.000,00$ & & $\mathrm{Rp}$ & $550.000,00$ \\
\hline Putty & $\mathrm{Rp}$ & $215.000,00$ & 0,25 & $\mathrm{Rp}$ & $53.750,00$ \\
\hline Sawing & $\mathrm{Rp}$ & $135.000,00$ & 0,5 & $\mathrm{Rp}$ & $67.500,00$ \\
\hline Grinding & $\mathrm{Rp}$ & $250.000,00$ & 0,5 & $\mathrm{Rp}$ & $125.000,00$ \\
\hline Vacum & $\mathrm{Rp}$ & $50.000,00$ & 1 & $\mathrm{Rp}$ & $50.000,00$ \\
\hline \multirow[t]{2}{*}{ Finishing } & $\mathrm{Rp}$ & $225.000,00$ & 0,5 & $\mathrm{Rp}$ & $112.500,00$ \\
\hline & & & 0,1 & & \\
\hline \multicolumn{3}{|c|}{ Total } & 3,85 & $\mathrm{Rp}$ & 958.750 \\
\hline
\end{tabular}

Tabel 4 adalah data biaya perawatan pattern setiap bulan yang digunakan pada setiap langkah sebelum adanya perbaikan. Selain biaya,waktu perbaikan cukup lama sehingga membuat biaya produksi semakin tinggi,perbaikan dilakukan dengan cara manual tanpa menggunakan mesin. Dalam perbaikan itu sendiri akan menjadikan potensi defect baru jika dalam perbaikan itu tidak berhasil. Pemilihan metode perbaikan tercepat dipilih untuk mengurangi tingginya biaya perbaikan. Dengan proses perbaikan yang efektif akan mengurangi kerugian perusahaan serta meningkatkan produktivitas dan keuntungan perusahaan.

\section{d. Diagram Sebab-Akibat (Fishbone Diagram)}

Dari penelitian terhadap daftar produk yang bermasalah di PT.PQR telah ditentukan bahwa rejection terbesar adalah knuckle arm steering dengan defect macro shrinkage. Pada tahap ini dilakukan analisa terhadap permasalahan yang ada di perusahaan. Gambar 7 adalah penjelasan dari analisa sebab akibat terhadap permasalahan terkait defect macro shrinkage.



Gambar 7. Diagram Sebab Akibat Permaslahan Defect 


\subsection{Tahap Do}

\subsubsection{Perencaan Perbaikan}

5W2H (What, Why, Where, When, Who, How, How Much) + Target adalah konsep yang digunakan untuk menjabarkan detail aktivitas yang akan dilakukan beserta target yang akan dicapai dari perencanaan perbaikan. Perencanaan perbaikan dilakukan berdasarkan dari analisis sebab akibat yang ada. Tabel 5 memperlihatkan perencanaan perbaikan dari penanggulangan terjadinya defect macro shrinkage pada produk knuckle arm steering.

Tabel 5. Perencanaan Perbaikan

\begin{tabular}{|c|c|c|c|c|c|c|c|c|c|c|}
\hline \multirow{2}{*}{ No. } & \multirow{2}{*}{ Faktor } & \multicolumn{2}{|c|}{ What } & \multirow{2}{*}{ Why } & \multirow{2}{*}{ How } & \multirow{2}{*}{ Where } & \multirow{2}{*}{ When } & \multirow{2}{*}{ Who } & \multirow{2}{*}{ How Much } & \multirow{2}{*}{ Target } \\
\hline & & Problem & Solusi & & & & & & & \\
\hline 1 & Methode & $\begin{array}{l}\text { Desain pattern } \\
\text { tidak standard }\end{array}$ & $\begin{array}{l}\text { Ubah desain } \\
\text { bermasalah }\end{array}$ & $\begin{array}{l}\text { Menyesuaikan } \\
\text { standard } \\
\text { pada produk }\end{array}$ & $\begin{array}{l}\text { Hitung ulang } \\
\text { kebutuhan } \\
\text { riser }\end{array}$ & Area produksi & $\begin{array}{l}\text { Jun'17 } \\
\text { Week } 1\end{array}$ & Engineering & Ro.35.158.750 & Menurunkan defect \\
\hline 2 & Machine & $\begin{array}{l}\text { Temperatur motten } \\
\text { iron rendah \& } \\
\text { slow pouring speed }\end{array}$ & $\begin{array}{l}\text { Temperatur tinggi } \\
\text { standard maksimum }\end{array}$ & $\begin{array}{c}\text { Antisipasi mesin } \\
\text { stop } \\
\text { saat tool change }\end{array}$ & $\begin{array}{c}\text { Uji coba } \\
\text { dengan } \\
\text { standard maksimum }\end{array}$ & Area produksi & \begin{tabular}{|l|} 
\\
Jun'17 \\
Week 2
\end{tabular} & Engineering & - & Menurunkan defect \\
\hline
\end{tabular}

\subsubsection{Pelaksanaan Perbaikan}

Analisis yang didapat dari permasalahan yang ada dan rencana yang telah disusun kemudian dilakukan perbaikan untuk mencapai tujuan dari penelitian. Tabel 6 menjelaskan detail hasil pelaksanaan rencana perbaikan yang mengacu pada perubahan metode dan perubahan proses mesin yang menyebabkan proses knuckle arm steering terdapat defect.

Tabel 6. Pelaksanaan Perbaikan

\begin{tabular}{|c|c|c|c|c|c|c|c|c|c|c|c|}
\hline \multirow{2}{*}{ No. } & \multirow{2}{*}{ Faktor } & \multicolumn{2}{|c|}{ What } & \multirow{2}{*}{ Why } & \multirow{2}{*}{ How } & \multirow{2}{*}{ Where } & \multirow{2}{*}{ When } & \multirow{2}{*}{ Who } & \multirow{2}{*}{ How Much } & \multicolumn{2}{|c|}{ Evaluasi } \\
\hline & & Problem & Solusi & & & & & & & Problem & Hasil \\
\hline 1 & Methode & $\begin{array}{l}\text { Desain pattern } \\
\text { tidak standard }\end{array}$ & $\begin{array}{l}\text { Ubah desain } \\
\text { bermasalah }\end{array}$ & $\begin{array}{c}\text { Menyesuaikan } \\
\text { standard pada produk }\end{array}$ & Kalkulasi kebutuhan riser & Area produksi & $\begin{array}{l}\text { Jun'17 } \\
\text { Week } 1\end{array}$ & Engineering & Rp.35.158.750,- & $\begin{array}{l}\text { Jun'17 } \\
\text { Week 3 }\end{array}$ & Terlaksana \\
\hline 2 & Machine & $\begin{array}{l}\text { Slow pouring speed \& } \\
\text { Temperatur molten } \\
\text { iron rendah }\end{array}$ & $\begin{array}{l}\text { Fast pouring speed } \\
\text { \&temperatur tinggi } \\
\text { standard maksimum }\end{array}$ & $\begin{array}{l}\text { Antisipasi mesin } \\
\text { stop saat tool change }\end{array}$ & $\begin{array}{l}\text { Uji coba dengan } \\
\text { temperatur maksimum }\end{array}$ & Area produksi & $\begin{array}{l}\text { Jun'17 } \\
\text { Week } 2\end{array}$ & Engineering & - & $\begin{array}{l}\text { Jun'17 } \\
\text { Week } 4\end{array}$ & Terlaksana \\
\hline
\end{tabular}

Pada masalah utamanya terdapat dua poin perbaikan yaitu perubahan metode layout pattern dan yang antisipasi defect yang terjadi karena mesin stop. Berikut adalah penjelasan secara detail solusi perbaikan yang dilakukan:

\section{a. Percobaan Pertama}

Pada percobaan perbaikan ini yaitu perubahan metode proses. Metode proses ini adalah menghitung ulang desain pattern yang berfokus pada volume riser dan gatting system. Gatting system merupakan sitem alir yang terdapat pada pattern pencetekan logam. Gambar 8 menjelaskan pada knuckle arm steering terdapat beberapa bagian yaitu cavity atau produk,riser, runner,slag trap dan sprue cup. 


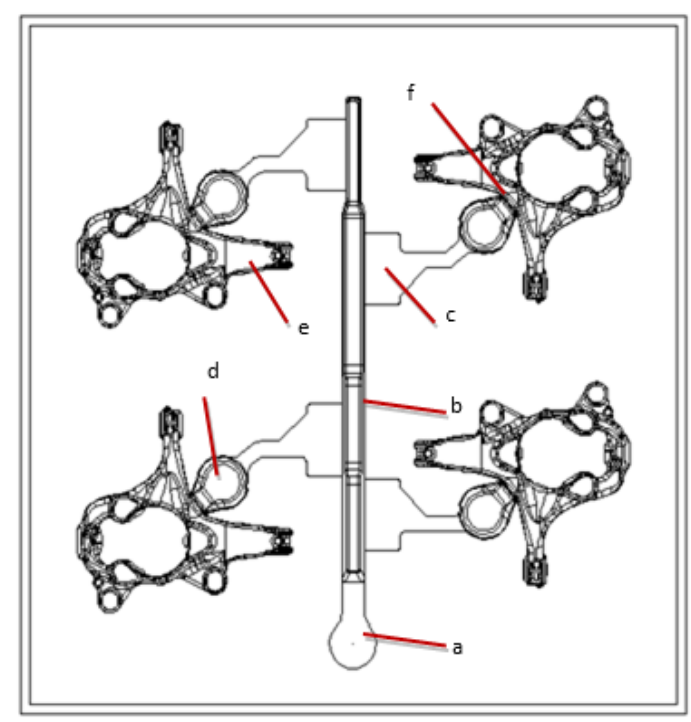

Ket : $\mathrm{a}=$ Sprue cup, $\mathrm{b}=$ runner, $\mathrm{c}=$ slag trap,

$$
\mathrm{d}=\text { riser }, \mathrm{e}=\text { cavity, } \mathrm{f}=\text { in gate }
$$

Gambar 8. Sketsa Gatting System Pattern Knuckle Arm Steering

Pada perbaikan ini dilakukan perhitungan gatting system dengan rumus untuk mendapatkan perbandingan sebelum dan sesudah dari gatting system. Tabel 7 adalah rumus yang dipakai PT.PQR dalam perhitungan gatting system.

Tabel 7. Rumus Perhitungan Gatting System

\begin{tabular}{|c|c|c|c|c|}
\hline Area & Rumus Perhitungan & \multicolumn{3}{|c|}{ Keterangan } \\
\hline \multirow{2}{*}{ Slag trap } & $\mathrm{A} 1=\frac{W \cdot 100000}{2}$ & \multirow{3}{*}{\multicolumn{2}{|c|}{$\begin{array}{l}\mathrm{A}=\text { Luas penampang }\left(\mathrm{mm}^{2}\right) \\
\mathrm{r}=\text { Jari-jari }(\mathrm{mm}) \\
\mathrm{t}=\text { Waktu pouring time }(10 \mathrm{~s})\end{array}$}} & $\rho=$ Massa jenis cairan $=6,9\left(\mathrm{~kg} / \mathrm{mm}^{3}\right)$ \\
\hline & $t . v \cdot m \cdot \rho$ & & & $\mathrm{W}=$ Berat casting $(\mathrm{kg})$ \\
\hline \multirow{3}{*}{ Riser } & $\mathrm{Mc}=\frac{A}{K}$ & & & $\mathrm{mr}=$ Massa riser \\
\hline & $M n-12 \mathrm{Mc}$ & $\mathrm{v}=$ Volume slag trap & $=100\left(\mathrm{~mm}^{3}\right)$ & $\mathrm{V}=$ Volume riser \\
\hline & $\mid \mathrm{VIIT}=1,2 . \mathrm{NIC}$ & = Volume runner & $=130\left(\mathrm{~mm}^{3}\right)$ & $\mathrm{M} r=$ Modulus riser \\
\hline Runner & $A=1,1 . A 1$ & $\mathrm{M}=$ Mampat aliran & $=0,43$ & Mc $=$ Modulus casting \\
\hline
\end{tabular}

Pada percobaan gatting system ini dilakukan perubahan volume riser dengan menambah tinggi riser dengan tujuan area solidifikasi terakhir berada pada riser sehingga defect macro shrinkage dapat dihilangkan.Gambar 9 memperlihatkanp perhitungan yang dimulai dari penentuan area solidifikasi atau pendinginan terakhir pada produk yang dihitung area luas volume terbesar.
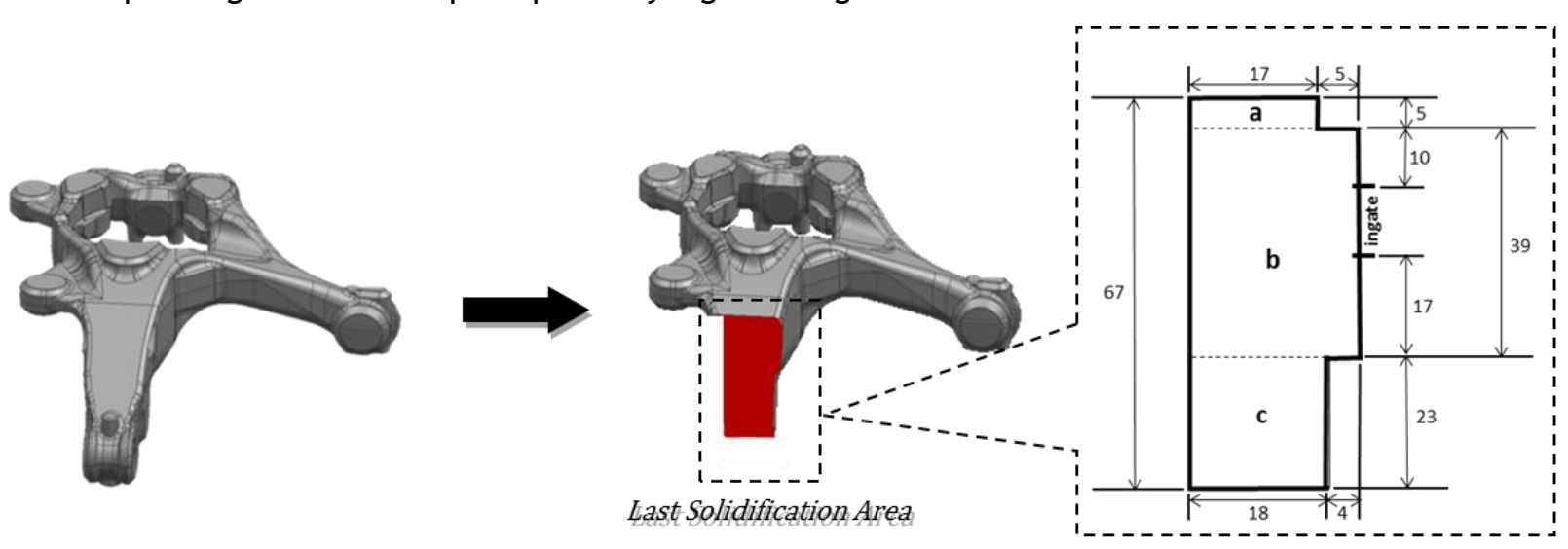

Gambar 9. Area Solidifikasi dan Luas Penampang Pada Knuckle Arm Steering 
Tabel 8 diperoleh modulus casting terbesar yaitu 11,44. Modulus ini digunakan untuk menghitung besaran ingate area,dimensi dan kebutuhan riser. Pada tabel 9 memperlihatkan perbaikan pattern dihitung perbandingan dari kalkulasi perhitungan dengan ukuran aktual yang ada,hasil perbandingan nantinya akan dipakai untuk perbaikan.

Tabel 8. Perhitungan Modulus Casting Knuckle Arm Steering

\begin{tabular}{|c|l|l|c|}
\hline Area & \multicolumn{1}{|c|}{ Luas Area (A) } & \multicolumn{1}{|c|}{ Keliling Area (K) } & $\begin{array}{c}\text { Modulus Casting } \\
(\mathbf{A} / \mathbf{K})\end{array}$ \\
\hline A & $17 \times 5=85 \mathrm{~mm}^{2}$ & $17+5+5=27 \mathrm{~mm}$ & 3,15 \\
\hline B & $39 \times 22=858 \mathrm{~mm}^{2}$ & $39+10+17+5+4=75 \mathrm{~mm}$ & 11,44 \\
\hline C & $17 \times 5=85 \mathrm{~mm}^{2}$ & $23+23+18=27 \mathrm{~mm}$ & 6,47 \\
\hline
\end{tabular}

Tabel 9. Perhitungan Perhitungan Kalkulasi dan Aktual Gating System

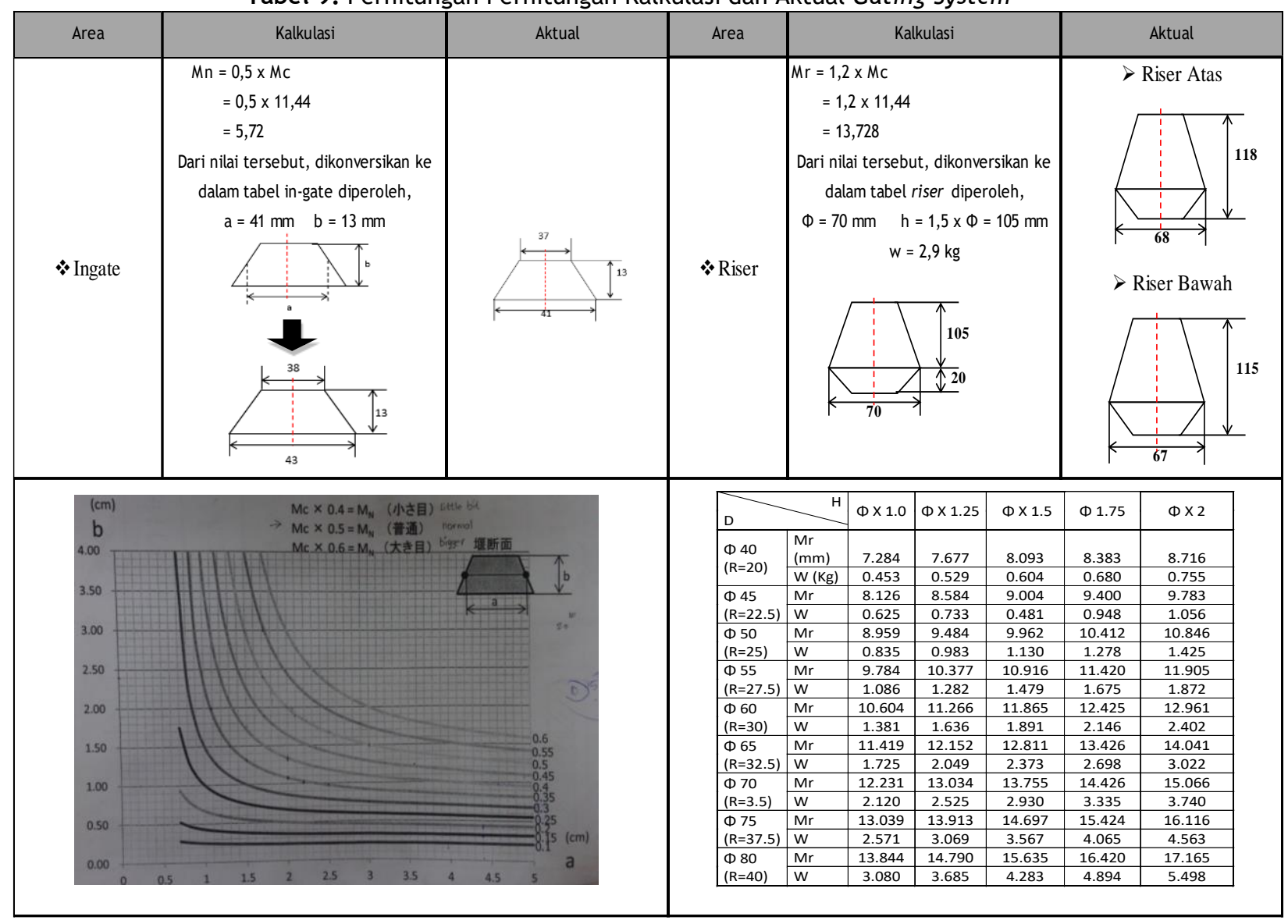

Gambar 10 menjelaskan hasil data defect macro shrinkage dari percobaan pertama, dimana masih terdapat defect walaupun sudah menunjukkan penurunan. Diperlukan percobaan selanjutnya sehingga penurunan defect lebih baik lagi.

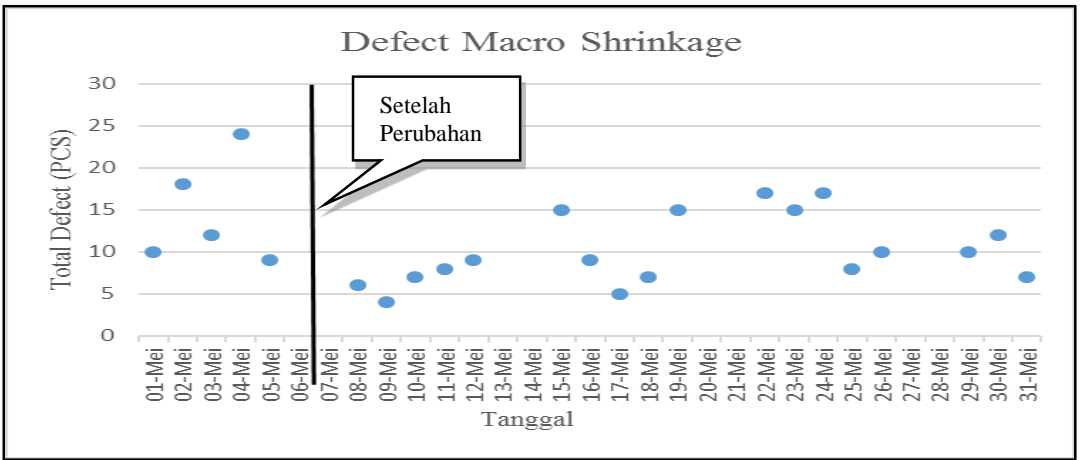

Gambar 10. Data Defect Macro Shrinkage Setelah Perbaikan Pertama 


\section{b. Percobaan Kedua}

Defect yang terjadi karena faktor mesin disebabkan ketika saat mesin berhenti untuk tool change dies atau pattern sehingga penuangan molten iron harus menunggu yang menyebabkan temperatur rendah dan pouring speed menjadi lama. Tabel 10 adalah sample data yang menampilkan hubungan total rejection dengan temperatur dan pouring speed knuckle arm steering yang selanjutnya diolah dengan regresi linier pada tabel 11 utuk menentukan target percobaan temperatur dan pouring speed. Pada regresi linier $p$-value menunjukkan angka signifikan yaitu $<0.05$ sehingga dapat disimpulkan bahwa variable masalah antara pouring speed dan temperatur terhadap defect dapat diterima serta memiliki korelasi.

Tabel 10. Data Pengambilan Sample Temperatur Molten Iron

\begin{tabular}{|c|c|c|c|c|c|c|c|c|c|c|c|}
\hline \multirow{2}{*}{\multicolumn{2}{|c|}{ Keterangan }} & \multicolumn{10}{|c|}{ Bulan Mei } \\
\hline & & 15 & 16 & 17 & 18 & 19 & 22 & 23 & 24 & 29 & 30 \\
\hline \multirow{3}{*}{ Temperatur $\left({ }^{\circ} \mathrm{C}\right)$} & $T \max$ & 1407 & 1415 & 1417 & 1415 & 1402 & 1403 & 1408 & 1404 & 1403 & 1409 \\
\hline & $\mathrm{T} \min$ & 1403 & 1413 & 1414 & 1414 & 1401 & 1401 & 1405 & 1402 & 1400 & 1406 \\
\hline & T ave & 1405 & 1414 & 1416 & 1415 & 1402 & 1402 & 1407 & 1403 & 1402 & 1408 \\
\hline \multicolumn{2}{|c|}{ Average Pouring Speed (Sec) } & 10 & 9 & 9 & 9 & 12 & 12 & 10 & 10 & 13 & 10 \\
\hline \multicolumn{2}{|c|}{ Total Reject (\%) } & 13,06 & 9,56 & 4,23 & 6,57 & 8,61 & 13,40 & 5,65 & 2,83 & 6,84 & 5,26 \\
\hline \multicolumn{2}{|c|}{ Defect Macro Shrinkage (\%) } & 1,87 & 1,28 & 0,60 & 1,10 & 2,48 & 2,56 & 1,63 & 2,53 & 2,14 & 1,62 \\
\hline
\end{tabular}

Tabel 11. Data Regresi Linier Knuckle Arm Steering

\begin{tabular}{|c|c|c|c|c|}
\hline \multicolumn{2}{|c|}{ Regression Statistics } & & & \\
\hline Multiple R & 0,945786123 & & & \\
\hline R Square & 0,89451139 & & & \\
\hline Adjusted R Square & 0,864371788 & & & \\
\hline Standard Error & 0,243857055 & & & \\
\hline Observations & 10 & & & \\
\hline \multicolumn{5}{|c|}{ ANOVA } \\
\hline & $d f$ & SS & MS & $F$ \\
\hline Regression & 2 & 3,529791029 & 1,764895515 & 29,67893762 \\
\hline Residual & 7 & 0,416263842 & 0,059466263 & \\
\hline \multirow[t]{2}{*}{ Total } & 9 & 3,946054872 & & \\
\hline & Coefficients & Standard Error & $t$ Stat & P-value \\
\hline Intercept & 180,53103 & 38,86333925 & 4,645278392 & 0,00235492 \\
\hline Pouring Speed & $-0,071352881$ & 0,105793458 & $-0,674454568$ & 0,05021666 \\
\hline Temperatur & $-0,126507276$ & 0,026956767 & $-4,692969202$ & 0,00222675 \\
\hline
\end{tabular}

Tabel 12 adalah hasil dari perhitungan korelasi temperatur dan pouring speed pada terhadap defect macro shrinkage hasil dari uji regresi linier. Dari tabel 12 dilakukan percobaan dengan temperatur menengah keatas $\left(1415-1430^{\circ} \mathrm{C}\right)$ diikuti pouring speed 8-10 detik dan temperatur standard bawah $\left(1400-1415^{\circ} \mathrm{C}\right)$ pouring speed 10-13 detik juga di uji coba temperatur menengah keatas (1415$\left.1430^{\circ} \mathrm{C}\right)$ diikuti pouring speed $10-13$ detik dan temperatur standar batas bawah $\left(1400-1415^{\circ} \mathrm{C}\right)$ pouring speed 8-10 detik. 
Tabel 12. Data Hasil Uji Regresi Linier

\begin{tabular}{|c|c|c|c|c|}
\hline \multicolumn{4}{|c|}{ Setting Target } & \multirow{2}{*}{ Target Rejection (\%) } \\
\hline \multicolumn{2}{|c|}{ Pouring Speed (sec) } & \multicolumn{2}{|c|}{ Temperatur $(\circ \mathrm{C})$} & \\
\hline \multirow{9}{*}{ 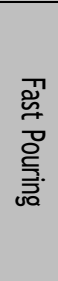 } & 10 & \multirow{9}{*}{  } & 1415 & 0,81 \\
\hline & 9 & & 1415 & 0,88 \\
\hline & 8 & & 1415 & 0,95 \\
\hline & 10 & & 1420 & 0,17 \\
\hline & 9 & & 1420 & 0,24 \\
\hline & 8 & & 1420 & 0,32 \\
\hline & 10 & & 1430 & $-1,09$ \\
\hline & 9 & & 1430 & $-1,02$ \\
\hline & 8 & & 1430 & $-0,95$ \\
\hline \multirow{9}{*}{ 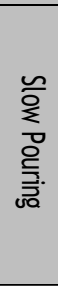 } & 11 & \multirow{9}{*}{ 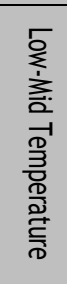 } & 1400 & 2,63 \\
\hline & 12 & & 1400 & 2,56 \\
\hline & 13 & & 1400 & 2,49 \\
\hline & 11 & & 1395 & 3,26 \\
\hline & 12 & & 1395 & 3,19 \\
\hline & 13 & & 1395 & 3,12 \\
\hline & 11 & & 1390 & 3,90 \\
\hline & 12 & & 1390 & 3,83 \\
\hline & 13 & & 1390 & 3,75 \\
\hline
\end{tabular}

Tabel 13 menyimpulkan bahwa dengan temperatur menengah keatas $\left(1415-1430^{\circ} \mathrm{C}\right)$ tidak terdapat defect macro shrinkage sedangkan untuk pouring speed tidak ada berpengaruh pada defect, akan tetapi untuk pouring speed tetap dijaga pada waktu 8-10 detik yang bertujuan menjaga degradasi penurunan temperatur.

Tabel 13. Hasil Percobaan Temperatur dan Pouring Speed

\begin{tabular}{|c|c|c|c|c|c|c|}
\hline Mold No. & Temp $\left({ }^{\circ} \mathrm{C}\right)$ & Pour Speed (s) & $\begin{array}{c}\text { Produk (pcs) } \\
\text { /Mold }\end{array}$ & Defect (pcs) & $\begin{array}{c}\text { Macro } \\
\text { Shrinkage (\%) }\end{array}$ & Ket. \\
\hline 1 & 1430 & 9 & 4 & 0 & $0 \%$ & \multirow{6}{*}{ 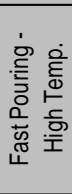 } \\
\hline 2 & 1429 & 9 & 4 & 0 & $0 \%$ & \\
\hline 3 & 1427 & 9 & 4 & 0 & $0 \%$ & \\
\hline 4 & 1425 & 9 & 4 & 0 & $0 \%$ & \\
\hline 5 & 1425 & 8 & 4 & 0 & $0 \%$ & \\
\hline 6 & 1423 & 10 & 4 & 0 & $0 \%$ & \\
\hline 7 & 1423 & 11 & 4 & 0 & $0 \%$ & \multirow{6}{*}{ 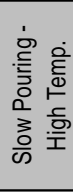 } \\
\hline 8 & 1422 & 11 & 4 & 0 & $0 \%$ & \\
\hline 9 & 1421 & 12 & 4 & 0 & $0 \%$ & \\
\hline 10 & 1420 & 13 & 4 & 0 & $0 \%$ & \\
\hline 11 & 1420 & 13 & 4 & 0 & $0 \%$ & \\
\hline 12 & 1419 & 13 & 4 & 0 & $0 \%$ & \\
\hline 13 & 1417 & 8 & 4 & 0 & $0 \%$ & \multirow{6}{*}{ 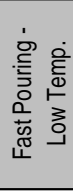 } \\
\hline 14 & 1415 & 8 & 4 & 0 & $0 \%$ & \\
\hline 15 & 1414 & 8 & 4 & 0 & $0 \%$ & \\
\hline 16 & 1414 & 9 & 4 & 1 & $25 \%$ & \\
\hline 17 & 1411 & 10 & 4 & 0 & $0 \%$ & \\
\hline 18 & 1410 & 9 & 4 & 1 & $25 \%$ & \\
\hline 19 & 1408 & 9 & 4 & 1 & $25 \%$ & \multirow{6}{*}{ 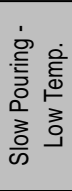 } \\
\hline 20 & 1405 & 11 & 4 & 2 & $50 \%$ & \\
\hline 21 & 1405 & 13 & 4 & 2 & $50 \%$ & \\
\hline 22 & 1403 & 12 & 4 & 1 & $25 \%$ & \\
\hline 23 & 1400 & 12 & 4 & 2 & $50 \%$ & \\
\hline 24 & 1400 & 13 & 4 & 3 & $75 \%$ & \\
\hline
\end{tabular}

\subsection{Tahap Check}

Proses check adalah pemeriksaan ulang hasil dari perbaikan yang telah dilakukan untuk diketahui hasil yang didapat. Tabel 14 menunjukkan biaya sebelum dan sesudah perbaikan, sedangkan tabel 15 data hasil setelah perbaikan dimana target total rejection sudah mencapai target. 
Tabel 14. Perbandingan Biaya Proses Perbaikan

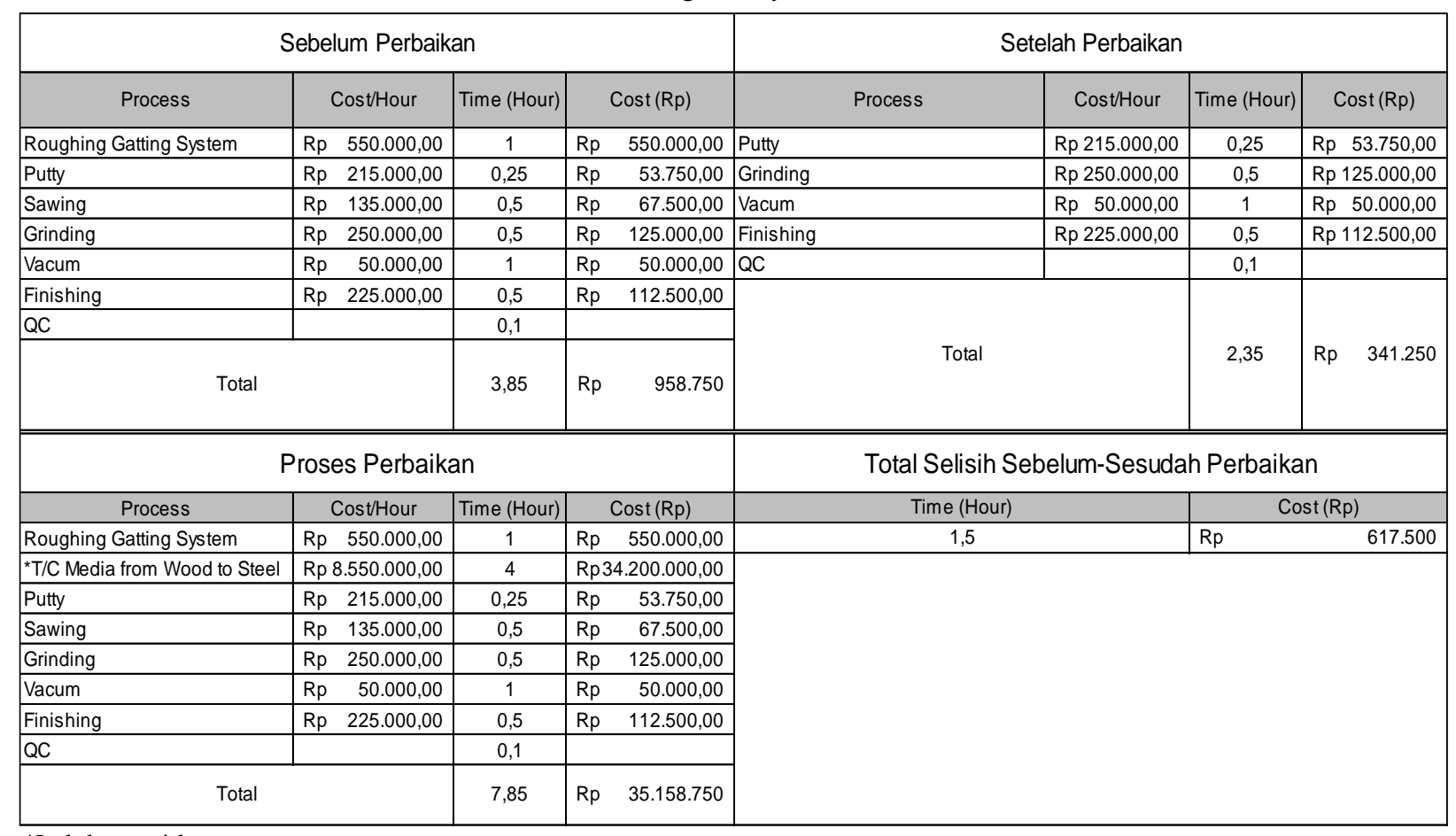

*Include material cost

Tabel 15. Aktual Presentase Rejection Knuckle Arm Steering

\begin{tabular}{|c|c|c|c|c|c|c|}
\hline \multirow{2}{*}{\multicolumn{2}{|c|}{ Periode Rejection }} & \multirow{2}{*}{$\begin{array}{c}\text { Sebelum Penelitian } \\
\text { Jan-Maret '17 }\end{array}$} & \multicolumn{3}{|c|}{ Selama penelitian } & \multirow{2}{*}{$\begin{array}{c}\text { Setelah } \\
\text { Penelitian } \\
\text { Juli '17 }\end{array}$} \\
\hline & & & April '17 & Mei'17 & Juni '17 & \\
\hline & Proses & 62139 & 20598 & 20025 & 20025 & 20375 \\
\hline & QTY Reject & 12450 & 2576 & 1876 & 1532 & 1024 \\
\hline & Presentase (\%) & $20,04 \%$ & $12,51 \%$ & $9,37 \%$ & $7,65 \%$ & $5,03 \%$ \\
\hline \multirow{15}{*}{ 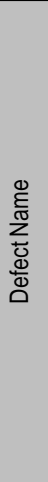 } & Macro Shrinkage & 5635 & 1543 & 254 & 20 & 5 \\
\hline & Slag Inclusion & 453 & 231 & 312 & 347 & 221 \\
\hline & Sand Inclusion & 2383 & 312 & 345 & 315 & 246 \\
\hline & Swell & 152 & 32 & 168 & 190 & 154 \\
\hline & Core Crack & & & & & \\
\hline & Dent & 1841 & 176 & 341 & 297 & 164 \\
\hline & Mold Broke & & & & & \\
\hline & Gas Holes & 3 & & 3 & & \\
\hline & Open Shrinkage & & & & & \\
\hline & Cold Lap & 731 & 42 & 122 & 98 & 62 \\
\hline & \begin{tabular}{|l|} 
Casting Crack \\
\end{tabular} & 1 & & & & \\
\hline & Sand Block & 1199 & 123 & 176 & 153 & 102 \\
\hline & Kake & 53 & 117 & 155 & 112 & 70 \\
\hline & Mold Crack & & & & & \\
\hline & Others & & & & & \\
\hline
\end{tabular}

\subsection{Proses Action}

Proses action adalah diterapkannya perbaikan yang telah terbukti hailnya dari permasalahan penelitian yang dilakukan. Evaluasi yang dilakukan dari hasil penelitian akan dilakukan standarisasi terhadap proses produksi. Dilakukannya standarisasi bertujuan untuk memudahkan proses produksi dimana hasil dari penelitian didapatkan standard baru yang lebih baik dari standard sebelumnya dalam proses pembutatan produk knuckle arm steering,dalam standard baru dipastikan defect yang terjadi tidak ada lagi dan total rejection membaik. 


\section{Simpulan}

Dari peneltian ini maka dapat diambil kesimpulan sebagai berikut : (1) Dari analisa data yang ada produk dengan presentase terbesar adalah knuckle arm steering dengan permasalahan defect macro shrinkage. (2) Penyebab tingginya defect pada knuckle arm steering adalah ketidakstabilan proses yang diperbaiki dengan perubahan ingate dan riser pattern serta perubahan standard pada pouring molten iron. (3) Efektivitas dari perubahan desain pattern pada knuckle arm steering dapat menurunkan defect macro shrinkage. Dengan mengubah volume riser menurunkan defect macro shrinkage hingga target rejection maksimal 5\% yang telah dibuat oleh PT. PQR. (4) Total rejection membaik pada bulan Juli 2017 dengan rasio 5\% dibandingkan sebelum perbaikan dengan rasio 10-20\%.

\section{Daftar Pustaka}

1. Asefeso, A. 2012. 5S Lean Manufacturing: (Key to Improving Net Profit).Swindon: AA Global Sourcing Ltd.

2. Chaudhari, T., and Raut, N., 2017. Waste Elimination by Lean Manufacturing. International Journal of Innovative Science, Engineering \& Technology, Vol. 4 Issue 5, pp 168-170.

3. Fontana, A., dan Gaspers, V., 2011. Lean Six Sigma For Manufacturing and Service Industries. Bogor : Vinchristo Publication.

4. Liker, J. K., 2003. The Toyota Way: 14 Management Principles from the World's Greatest Manufacturer. New York: McGraw Hill Professional. 